\title{
Editorials
}

\section{Protecting health in hard times}

BMJ 2010; 341 doi: http://dx.doi.org/10.1136/bmj.c5308 (Published 29 September 2010) Cite this as: BMJ 2010;341:c5308

- Article

- Related content

- Metrics

- Responses

- Peer review

-

Martin McKee, professor of European public health1, David Stuckler, research fellow2, Jose M Martin-Moreno, director of programme management ${ }^{3}$

\section{Author affiliations}

martin.mckee@Ishtm.ac.uk

\section{Europe's health ministers exchange experiences on the impact of the economic crisis}

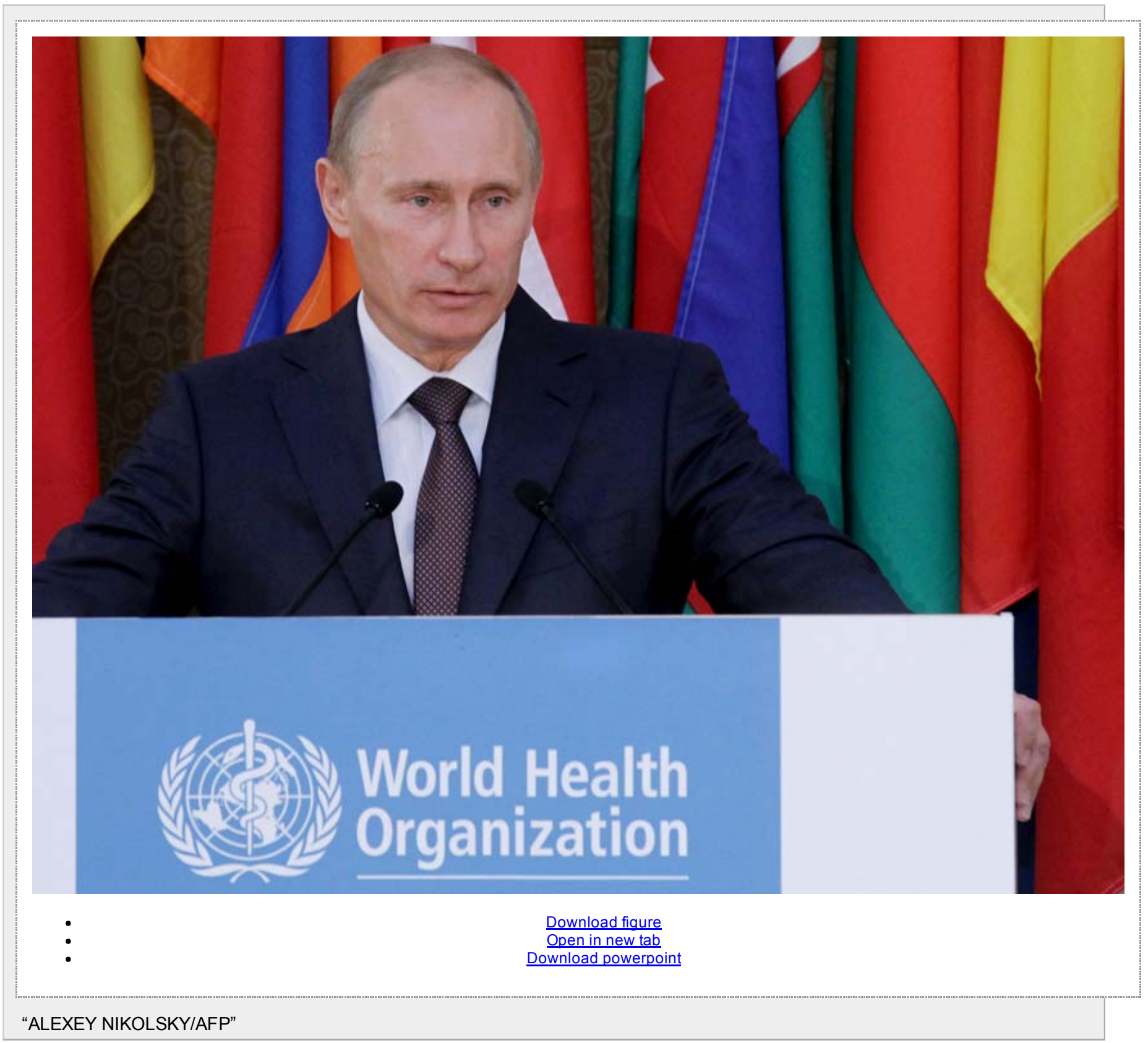

Health ministers from across Europe came together in Moscow in September at the 60th meeting of the European regional committee of the World Health Organization. High on their agenda was the ongoing economic difficulty facing many of their countries. Their experiences varied. Some had seen their budgets frozen whereas others had experienced real cuts. A fortunate few, however, had seen budget increases, as a 
result of recognition by their cabinet colleagues of the necessity of protecting the most vulnerable at times of crisis. As ministers and institutional partners shared experiences and challenges, they endorsed WHO Europe's call to move forward as a region under a consolidated European Health Policy, which will foster effective and coordinated action to bolster health systems in the face of evolving challenges.

Three main messages on the financial crisis emerged from member states during a technical briefing devoted to this topic. The first was the need for health ministers and their advisers to engage actively in discussions about the economy. There was confusion among politicians, media commentators, and the public about the differences between deficit and debt (for example, the United Kingdom has a high deficit but relatively low government debt) and between debt held by government, banks, the non-financial corporate sector, and households.1 Terms such as "unsustainable" are used widely to describe levels of debt even though in most western European countries they are well below the International Monetary Fund's definition of unsustainability.2 Debate on how to respond is often oversimplified, with little awareness of historical evidence, 1 and, as the IMF has recently noted, it may not give sufficient priority to the social consequences of retrenchment. 2 There was particular concern that some finance ministries, urged on by the media, are using the economic difficulties to pursue an underlying objective of shrinking the state.

The second message was the need to protect those who are the most vulnerable. Epidemiological research shows the profound health consequences of unemployment and, although less well recognised, fear of unemployment.3456 Research on previous economic crises shows that higher unemployment is associated with increased suicide rates. 67 Yet it also shows that, with increases in social welfare and in particular active labour market policies that keep people in work or return them rapidly to the workforce, this is not inevitable. This is apparent in a comparison of Spain and Sweden, both of which faced severe economic problems in the late 1980s and early 1990s. Whereas Spain saw a relative increase in suicides in this period, in Sweden, with its strong welfare state and active labour market policies, the long term decline in suicides continued uninterrupted. Those present at the briefing supported a call from one international agency present to "pump resources into mental health services," reflecting concerns that in many countries they had been weak even before the current economic difficulties.

Delegates gave many examples of how they were seeking to do this. The Moldovan health ministry has successfully negotiated additional funding for the health insurance fund from the finance ministry. The Icelandic government, facing an extremely severe crisis, has negotiated cuts to the health budget with the IMF that were only half as large as in other areas. A few countries had been forced to cut salaries of health workers but many, including Greece and Ireland, were looking at how to cut the large bill for drugs using reference pricing (paying a standard price for all drugs with the same active ingredient). This approach could lead, indirectly, to price reductions for other countries that benchmark their prices internationally. As one international agency noted, there is still substantial scope to save costs through greater generic substitution. However, the smaller countries drew attention to the difficulty they faced in negotiating with the drug industry. 8

The third message was that the crisis could be used to implement desired reforms that had proved difficult in the past. The Latvian government has engaged in a long awaited, and much needed, reduction in the number of hospitals and an upgrading of emergency care. The Spanish government plans to use a new public health law to shift resources away from individual (and often expensive and ineffective) prevention measures, such as screening for prostate cancer, towards population based health protection and health promotion programmes of known effectiveness.9 Special emphasis is placed on integrating public health practice with primary care and supporting healthy choices.

Such measures should not be confined to the health sector. Recalling the concept of "health in all policies" set out by the Finnish presidency of the European Union in 2006,10 ministers stressed the importance of recognising how health and health services contribute to economic growth and how developments in other sectors contribute to health. Thus, the World Bank drew attention to the road building programme in Russia, a private-public partnership designed to create employment and make driving safer as part of efforts to reduce traffic accidents.11

Although the sustainability of health systems and the methods to deliver health care are debated even in times of economic growth, the current financial crisis has raised the pitch of the debate. This was acknowledged in the presentation of the proposal for the WHO European region's new European Health Policy, in which the financial sustainability of health systems was cited as one of seven primary challenges currently facing health systems. These challenges are best tackled through a renewed commitment to evidence based public health and public health infrastructures12; the strengthening of health systems and the empowerment of health ministries; collaboration between national and regional partners; and wisdom accumulated from a long tradition of past public health initiatives, which has created an opportunity for shared learning across Europe. Above all, the ability of health systems to cope with budget shortfalls in the face of higher population needs will require a coalescence of technical, political, and social leadership, spearheaded by national health ministries but extending to everyone with the potential to improve health.

\section{Notes}

Cite this as: $B M J 2010 ; 341: c 5308$

\section{Footnotes}

- Competing interests: All authors have completed the Unified Competing Interest form at www.icmje.org/coi_disclosure.pdf (available on request from the corresponding author) and declare: no support from any organisation for the submitted work; JMM-M is employed by WHO, MM and DS receive funding from WHO, MM and JMM-M led the technical briefing described; no other relationships or activities that could appear to have influenced the submitted work. 
- Provenance and peer review: Commissioned; not externally peer reviewed.

\section{References}

1. $\lrcorner$ Stuckler D, Basu S, McKee M, Suhrcke M. Responding to the economic crisis: a primer for public health professionals. $J$ Public Health Policy2010;32:298-306.

2. $\downarrow$ Wiggle room: the IMF offers indebted governments some reassurance. Economist 2010. www.economist.com/node/16944929? story id=16944929\&fsrc=rss.

3. $\downarrow$ McKee-Ryan M, Song Z, Wanberg CR, Kinicki AJ. Psychological and physical well-being during unemployment: a meta-analytic study. J Appl Psychol2005;90:53-76. CrossRef Medline Web of Science

4. $\downarrow$ Murphy G, Athanasou, JA. The effect of unemployment on mental health. J Occup Organization Psycho/1999;72:83-99. CrossRef

5. $\downarrow$ Perlman F, Bobak, M. Assessing the contribution of unstable employment to mortality in posttransition Russia: prospective individual-level analyses from the Russian longitudinal monitoring survey. Am J Public Health2009;99:1818-25. CrossRef Medline Web of Science

6. $\downarrow$ Stuckler D, Basu S, Suhrcke M, Coutts A, McKee M. The public health impact of economic crises and alternative policy responses in Europe. Lancet 2009;374:315-23. CrossRef Medline Web of Science

7. $\downarrow$ Stuckler D, Basu S, McKee M. How government spending cuts put lives at risk. Nature2010;465:289. Medline Web of Science

8. $\lrcorner$ Brabant M. Insulin giant pulls medicine from Greece over price cut. BBC 2010. www.bbc.co.uk/news/10189367.

9. $\downarrow$ De Lago M. Spanish reform bill looks to prevention to ensure viability of health service. BMJ2010;341:c3701. FREE Full Text

10. $\downarrow$ Ståhl TWM, Ollila E, Lahtinen E, Leppo K, eds. Health in all policies: prospects and potentials. Ministry of Social Affairs and Health and European Observatory on Health Systems and Policies, 2006.

11. $\downarrow$ Marquez P, Salakhutdinova, SK. Confronting "death on wheels": making roads safe in the Russian Federation. World Bank, 2009.

12. $\downarrow$ Martin-Moreno JM, Alfonso-Sanchez JL, Harris M, Gonzalez Lopez-Valcarcel B. The effects of the financial crisis on primary prevention of cancer. Eur J Cancer2010;46:2525-33. CrossRef Medline

- $y$ Tweet

- f Like 0

- $\mathrm{G}+1 \quad 0$

\section{Article tools}

\section{0 responses}

- שேRespond to this article

- BPrint

- Alerts \& updates

\section{Article alerts}

Please note: your email address is provided to the journal, which may use this information for marketing purposes.

\section{Log in or register:}

Username *

Password *

Log in

$\underline{\text { Register for alerts }}$

(1) If you have registered for alerts, you should use your registered email address as your username

- Citation tools

\section{Download this article to citation manager}

McKee Martin, Stuckler David, Martin-Moreno Jose M. Protecting health in hard times BMJ 2010; 341 :c5308

- BibTeX (win \& mac)

Download

- EndNote (tagged)

- EndNote 8 (xml)

- RefWorks Tagged (win \& mac)

Download

- RIS (win only)

Download

- Medlars 